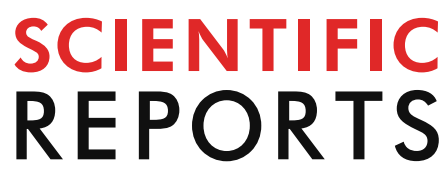

natureresearch

Check for updates

\title{
Geographic variation
} in cardiometabolic risk factor prevalence explained by area-level disadvantage in the Illawarra-Shoalhaven region of the NSW, Australia

\author{
Renin Toms ${ }^{1,2 凹}$, Darren J. Mayne ${ }^{11,2,3,4}$, Xiaoqi Feng ${ }^{2,5,6}$ \& Andrew Bonney ${ }^{1,2}$
}

Cardiometabolic risk factors (CMRFs) demonstrate significant geographic variation in their distribution. The study aims to quantify the general contextual effect of the areas on CMRFs; and the geographic variation explained by area-level socioeconomic disadvantage. A cross sectional design and multilevel logistic regression methods were adopted. Data included objectively measured routine pathology test data between years 2012 and 2017 on: fasting blood sugar level; glycated haemoglobin; total cholesterol; high density lipoprotein; urinary albumin creatinine ratio; estimated glomerular filtration rate; and body mass index. The 2011 Australian census based Index of Relative Socioeconomic Disadvantage (IRSD) were the area-level study variables, analysed at its smallest geographic unit of reporting. A total of 1,132,029 CMRF test results from 256,525 individuals were analysed. After adjusting for individual-level covariates, all CMRFs significantly associated with IRSD and the probability of higher risk CMRFs increases with greater area-level disadvantage. Though the specific contribution of IRSD in the geographic variation of CMRF ranged between 57.8 and $14.71 \%$, the general contextual effect of areas were found minimal (ICCs $0.6-3.4 \%$ ). The results support universal interventions proportional to the need and disadvantage level of populations for the prevention and control of CMRFs, rather than any area specific interventions as the contextual effects were found minimal in the study region.

The prevalence of cardiometabolic risk factors (CMRFs) varies geographically ${ }^{1,2}$. Previous research has reported higher prevalence of CMRFs in certain localities: typically in areas of higher socioeconomic disadvantage ${ }^{3-23}$. However, frequently these studies have been based on measures of association or geographical variance rather than reporting clustering or the share of the total variance that is at the area-level ${ }^{3-23}$. Quantifying the clustering and the proportion of geographic variation in CMRFs contributed by area-level socioeconomic disadvantage can aid in designing appropriate area-level approaches to help prevent CMRFs. Chronic and uncontrolled CMRFs predispose individuals to the development of cardiovascular disease (CVD), which continues to be the leading cause of health care expenditure and premature mortality worldwide ${ }^{24}$.

In Australia, a social gradient is observed in the prevalence of many chronic conditions including various CMRFs (e.g.diabetes and chronic kidney disease) ${ }^{25}$. Generally, Australians enjoy better health than people in many other countries in the world. However, within Australia this better health is not equally distributed ${ }^{26}$. It is

\footnotetext{
${ }^{1}$ School of Medicine, University of Wollongong, Wollongong, NSW 2522, Australia. ${ }^{2}$ lllawarra Health and Medical Research Institute, Wollongong, NSW 2522, Australia. ${ }^{3}$ Public Health Unit, Illawarra Shoalhaven Local Health District, Warrawong, NSW 2502, Australia. ${ }^{4}$ School of Public Health, The University of Sydney, Sydney, NSW 2006, Australia. ${ }^{5}$ Population Wellbeing and Environment Research Lab (PowerLab), School of Health and Society, Faculty of Social Sciences, University of Wollongong, Wollongong, Australia. ${ }^{6}$ School of Public Health and Community Medicine, University of New South Wales, Sydney, NSW, Australia. ${ }^{\varpi}$ email: rmbst288@uowmail.edu.au
} 
often-reported that socioeconomically disadvantaged individuals in Australia, on average, experience a greater disease burden than their less disadvantaged counterparts ${ }^{25-28}$. This tendency is also evident at a contextual level when studies have investigated association of CMRFs with area-level socioeconomic disadvantage in Australia ${ }^{5,7}$ and globally $4,9,10,12,14,16-18,20,23,29-33$.

Consistent with this, men from highly urbanised environments have been reported to have higher incidence of coronary heart disease with increasing residential area socioeconomic disadvantage, after adjusting for individual characteristics $^{18}$. Also, lower area-level disadvantage has been reported as being associated with lower prevalence of some behavioural cardiac risk factors such as smoking, physical inactivity and obesity etc. in some studies $9,10,34$. Most of the reported associations of CMRFs with area-level socioeconomic disadvantage were independent of individual-level characteristics such as age and educational attainment. Even though the area-level associations of CMRFs were significant in these studies, the results were often dependent on the CMRF analysed, the measures of area-level socioeconomic disadvantage and the geographic scale at which associations were examined ${ }^{35}$.

Multilevel analyses of CMRFs based on the average measures of association or variation alone are insufficient to report the geographical variance as similar associations were possible with very different scenarios of area variance $^{36}$. Multilevel findings extending on the general contextual effects and reporting the proportion of the total area-level variance along with the measures of clustering and the average measures of association or variation are appropriate and informative in reporting area-level influences, but less common ${ }^{23,36-38}$. To differentiate the relative importance of individual versus area-level interventions for the prevention and control of CMRFs, the geographical component of the total individual risk variance has to be identified in a multilevel approach.

Therefore, the aims of this study are to (1) quantify the general contextual or geographic effect of areas on CMRFs, over and above their individual-level compositions; and to (2) quantify the geographic variation across multiple CMRFs specifically explained by area-level socioeconomic disadvantage, within the IllawarraShoalhaven region of NSW Australia. Quantification of the general contextual effect and the variation specifically explained by area-level socioeconomic disadvantage will assist our understanding of the socioeconomic context of CMRFs in the study region and provide guidance for health service commissioning more generally nationally.

\section{Methods}

A cross-sectional multilevel design was adopted to account for the hierarchical nature of the data and analyses. No informed consent were obtained for the individual-level data used in this study, as the study used existing data which were already de-identified. The study was approved by the University of Wollongong and Illawarra and Shoalhaven Local Health District Health and Medical Human Research Ethics Committee (HREC protocol No: 2017/124). All the methods and analyses were performed meeting the relevent ethical guidelines and regulations of the committee.

Study area and data. The study was conducted in the Illawarra-Shoalhaven region of the New South Wales (NSW) state in Australia. The Illawarra-Shoalhaven region is a coastal plain along the south-east border of NSW; situates at the immediate south of the metropolitan boundaries of Sydney; and encompasses multiple regional cities, towns and rural areas. This region covers a land area of $5,615 \mathrm{~km}^{2}$, and had an estimated residential population of 369,469 at the time of the 2011 Australian Census of Population and Housing conducted by the Australian Bureau of Statistics (ABS) ${ }^{39}$. Statistical Area level 1 (SA1), the smallest geographical unit of the 2011 census data release, was the area-level unit of analysis in this study ${ }^{39}$. SA1s typically have a population size of 200 to 800 persons (average 400), and the Illawarra-Shoalhaven region covers a total of 980 conterminous SA1s ${ }^{39}$.

The CMRF test data in this study were extracted from the Southern IML Research (SIMLR) Study database, which is comprised of de-identified and internally linked pathology results from a major network of pathology services in the study region. The individual-level data in SIMLR database are geocoded to their corresponding SA1 areas, but not to their residential address, for privacy and confidentiality concerns. More details on this data source, procurement and access are published elsewhere ${ }^{7}$. The CMRF test data were extracted for non-pregnant individuals aged 18 years or older presenting for testing between 01 January 2012 and December 2017. Only the most recent test result was included if an individual had undergone the same test multiple times in this data period. Test data with missing details on the individual and area-level factors analysed in this study were excluded from the analyses.

Variables. Outcome variable. Results of the CMRF tests were the individual-level outcome variables. Data on the seven CMRF tests analysed in this study included: fasting blood sugar level (FBSL); glycated haemoglobin (HbA1c); total cholesterol (TC); high density lipoprotein (HDL); urinary albumin creatinine ratio (ACR); estimated glomerular filtration rate (eGFR); and objectively-measured body mass index (BMI). These CMRF test results were dichotomised into higher risk and lower risk values based on the current national and international guidelines on risk definitions (Table 1).

Study variable. The 2011 ABS census based Index of Relative Socioeconomic Disadvantage (IRSD) of the SA1s was the study variable. IRSD summarises a range of measures of relative socioeconomic disadvantage of people and households within SA1s and includes: level of income; education; employment; family structure; disability; housing; transportation; and internet connection ${ }^{45}$. This study uses IRSD reported as quintiles; the lowest quintile (Q1) indicating the most disadvantaged SA1s and the highest quintile (Q5) the least disadvantaged SA1 $\mathrm{s}^{45}$. The IRSD quintiles in the study were derived by ABS from the distribution of IRSD scores for the IllawarraShoalhaven region based on the 2011 census. The study region has a diverse IRSD profile with representation across IRSD scores in comparison with Australia as a whole, making the region useful for population-level studies ${ }^{46}$. 


\begin{tabular}{|l|l|l|}
\hline & Higher risk CMRFs & Definition \\
\hline 1 & High FBSL & FBSL $\geq 7.0 \mathrm{mmol} / \mathrm{L}^{40}$ \\
\hline 2 & High HbAlc & $\mathrm{HbAlc}>7.5 \%{ }^{40}$ \\
\hline 3 & High TC & $\mathrm{TC} \geq 5.5 \mathrm{mmol} / \mathrm{L}^{41}$ \\
\hline 4 & Low HDL & $\mathrm{HDL}<1 \mathrm{mmol} / \mathrm{L}^{42}$ \\
\hline 5 & High ACR & $\mathrm{ACR} \geq 30 \mathrm{mcg} / \mathrm{L}$ to $\mathrm{mg} / \mathrm{L}^{43}$ \\
\hline 6 & Low eGFR & $\mathrm{eGFR}<60 \mathrm{~mL} / \mathrm{min} / 1.73 \mathrm{~m}^{2}{ }^{43}$ \\
\hline 7 & Obesity & $\mathrm{BMI} \geq 30 \mathrm{~kg} / \mathrm{m}^{2} 44$ \\
\hline
\end{tabular}

Table 1. Definitions of higher risk CMRFs test results. CMRFs Cardiometabolic risk factors, FBSL Fasting Blood Sugar Level, HbA1c Glycated Haemoglobin, TC Total Cholesterol, HDL High Density Lipoprotein, ACR Albumin Creatinine Ratio, eGFR estimated Glomerular Filtration Rate, BMI Body Mass Index.

Covariates. Analyses were adjusted for sex (male and female) and age group (18-29 years, 30-39 years, 40-49 years, 50-59 years, 60-69 years, 70-79 years, $80+$ years) of each individual at the time of the pathology collection of the CMRFs tests analysed in his study.

Statistical analyses. Initially, descriptive statistics of all individual and area-level variables were performed. Thereafter, single level and multilevel logistic regression models were fitted for the CMRF test data of individuals (Level 1), nested within SA1s (Level 2). For each of the seven CMRFs analysed in this study, a hierarchy of four multilevel models at SA1 level were fit that included fixed effects for age, sex and IRSD and random effect (intercept) for SA1. Model 0 was a single level model adjusted for age and sex; Model 1 (M1) was null model at level 2; Model 2 (M2) adjusted for age and sex at level 2; Model 3 (M3) adjusted for the area-level study variable (IRSD) only at level 2; and the final model Model 4 (M4) included both M2 and M3 covariates (age, sex and IRSD) at level 2. The estimated regression coefficients of the derived models were exponentiated to calculate odds ratios (ORs).The goodness of fit of the models were identified using Likelihood Ratio Tests (LRT) at $p<0.05$ level of significance. The general equation of the fully adjusted model is:

$$
\begin{aligned}
& \mathrm{y}_{\mathrm{ij}} \sim \operatorname{Binomial}\left(1, \pi_{\mathrm{ij}}\right) \\
& \operatorname{logit}\left(\pi_{\mathrm{ij}}\right)=\beta_{0}+\beta_{1} \mathrm{Age}_{\mathrm{ij}}+\beta_{2} \operatorname{Sex}_{\mathrm{ij}}+\beta_{3} \operatorname{IRSD}_{\mathrm{ij}}+\mathrm{u}_{\mathrm{j}} \\
& \mathrm{u}_{\mathrm{j}} \sim \mathrm{N}\left(0, \tau_{\mathrm{u}}^{2}\right)
\end{aligned}
$$

where $y_{i j}$ denote the binary response of CMRF test outcome (as 'higher risk' or 'lower risk', based on the adopted definitions) for individual $i$ in the area (SA1) $j ; \pi_{i j}$ denotes the probability that individual $i$ in area (SA 1$) j$ has a 'higher risk' CMRF test outcome given their individual-level $a g e_{i j}$ and $\operatorname{sex}_{i j}$, and their area-level IRSD index. The $\beta_{1}, \beta_{2}, \beta_{3}$ are the regression coefficients which measure the associations between the log-odds of the CMRF outcome and each covariate all else equal, and when exponentiated these are translated to $\mathrm{ORs}^{36} \cdot u_{j}$ is the random effect for the area (SA1) $j$ and $\tau^{2}$ is the area level variance, which has to be estimated.

Model comparison. The Akaike Information Criterion (AIC) was used to evaluate model fit. The derived multilevel models were compared for: area-level variance $\left(\tau^{2}\right)$ at SA1 (level 2) level; proportional change in variance (PCV); Intra-cluster Correlation Coefficients (ICC); Median Odds Ratios (MORs); area under the receiver operating characteristic (AUC) curve; and the change in AUC.

The $\tau^{2} s$ of the multilevel models were initially identified from each models. PCVs were calculated for models M2s to M4s relative to M1s. The ICCs of the fitted models were calculated using the latent variable approach ${ }^{47}$. This approach assumes that a latent continuous outcome underlies the observed dichotomous outcomes and it is this latent outcome for which the ICC is calculated and interpreted. The ICC measured the expected correlation in CMRF outcomes between two individuals from the same SA1. The higher the ICC, the more relevant area-level context is for understanding individual latent outcome variation ${ }^{36}$. The MOR is calculated as an alternative way of interpreting the magnitude of area-level variance. The MOR translated the area-level variance which were estimated on the log-odds scale to the commonly used OR scale. The MOR result value is interpreted as the median increased odds of identifying the outcome if an individual move to another SA1 with higher risk. Thus, the higher the MOR the greater the general area-level effect and it will equal to 1 in the absence of area-level variance ${ }^{36}$. The general contextual effect of the geographic areas over and above their individual-level composition of the higher risk CMRFs, is obtained through the measure of clustering (ICC) in M2s. The geographic variance and ICC in the null models (M1s) of higher risk CMRFs may depend on both the contextual and individual-level variables. Therefore, M2s of the higher risk CMRFs which adjusted for individual-level attributes is better to provide information on the 'general contextual effect' of the areas. The unique contribution of the area-level study variable (IRSD) to the area-level variance of higher risk CMRFs were assessed through the PCVs between M2s and M4s.

The receiver operating characteristic (ROC) curves are created by plotting the true positive rates (TPR) i.e. sensitivity, against the false positive rates (FPR), i.e. 1 specificity for different binary classification thresholds of the predicted probabilities in all the models ${ }^{48}$. Post-estimation, predicted probabilities $\left(\pi_{\mathrm{ij}}\right)$ are calculated for 


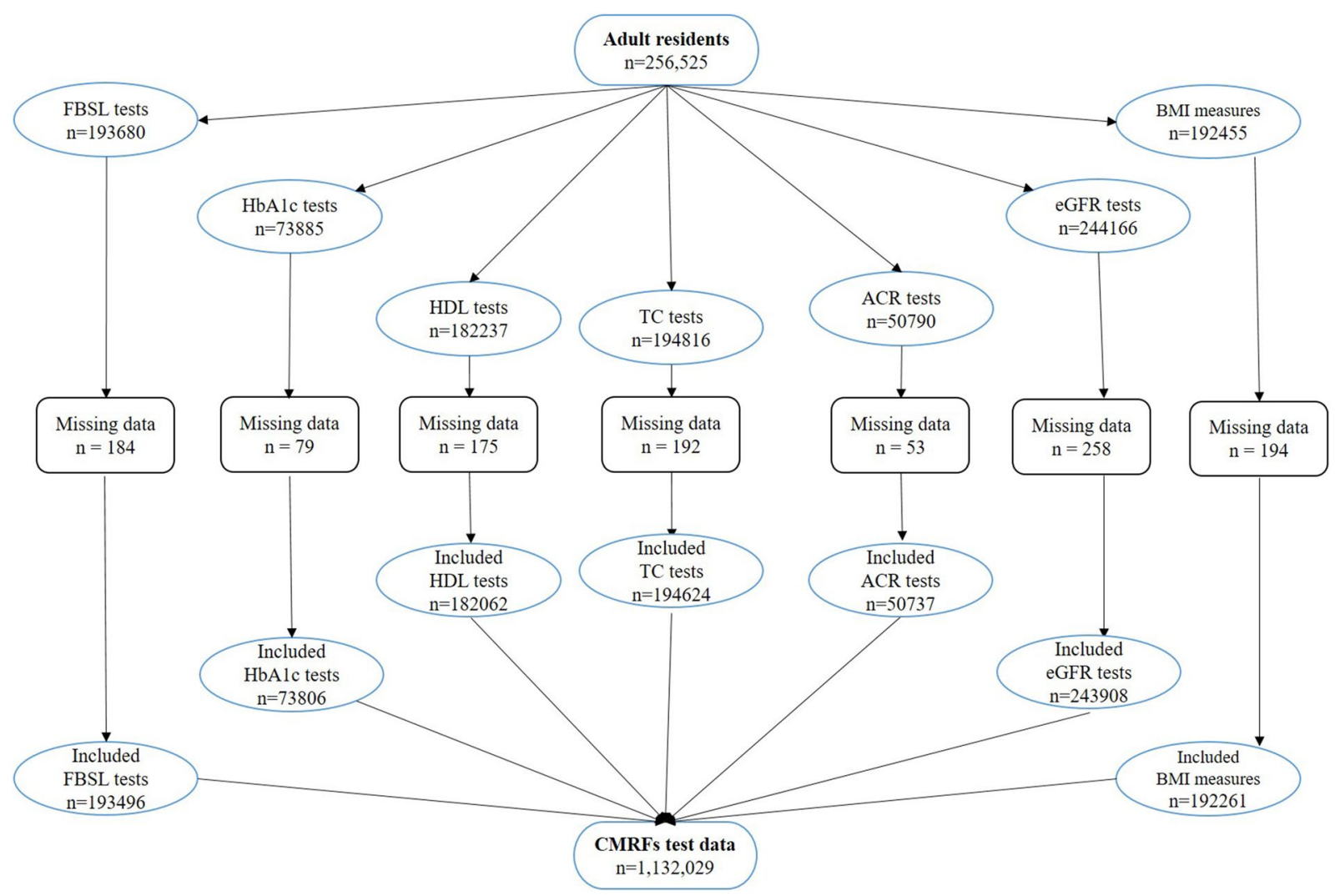

Figure 1. Flow chart of the included/excluded tests in the CMRFs test data.

each individual and are used to calculate the AUC for the model. The AUCs of the models measure the capacity of the models to correctly classify individuals with or without the outcome of a higher risk CMRFs analysed in this study, as a function of their predicted probabilities ${ }^{36}$. The AUC values range from 1 and 0.5 , where 1 is the perfect predictive discrimination and 0.5 have no predictive power ${ }^{49}$. The AUCs also indicate the general contextual effects and can be compared it to the ICC and the MOR values ${ }^{36}$. The added value of knowing an individual's area of residence besides individual-level information (age and sex) can be obtained through the AUC change in Model 2 in reference to Model 0, where a higher AUC change would indicate higher relevance of areas in relation to CMRFs.

Statistical package. All analyses were performed using R version 3.4.4. (R Foundation for Statistical Computing, Vienna, Austria $)^{50}$. Multi-level models were fit using the glmer function in the $l m e 4$ package ${ }^{51}$ likelihood ratio tests were calculated using the lrtest function in the lmtest package ${ }^{52}$,and ROC curves using the roc function in the pROC package ${ }^{53}$.

\section{Results}

A total of 1,132,029 CMRFs test data which belong to 256,525 individuals were extracted for the analyses. Figure 1 provides a flow chart of the individual tests in CMRF test data. The mean number of tests per person was 4.4. After removing $1,162(1.0 \%)$ test results data with missing details, a total of $1,130,894$ tests were included in the analytic data set.

Table 2 provides details of the missing data and test data distribution of each CMRF tests. Most frequently missing data were the IRSD indices from SA1s in the study area for which an IRSD index was not available from ABS 2011 census either due to low populations or poor data quality ${ }^{54}$.

Tables 3 and 4 shows the frequencies and relative frequencies of CMRF tests results. Overall, the higher risk frequencies of all CMRFs increased with increasing area-level socioeconomic disadvantage, except for TC which demonstrated an inverse trend.

Single and multilevel models for each of the CMRFs analysed in this study are presented in Tables 5, 6, 7, 8, 9, 10 and 11. After adjusting for the covariates, all seven CMRFs were found to be significantly associated with area-level IRSD in the study region. For all but one variable the associations were positive (i.e. increased with area-level disadvantage). TC was the exception; being inversely associated with area-level disadvantage, with the most disadvantaged quintile (Q1) displaying the lowest odds for higher risk test results. Among the covariates, there was no significant association between gender and higher risk test results of eGFR or BMI. It was also noted that the odds of higher risk eGFR tests results accelerated with increasing age group, and the 80+ age group demonstrated a very high odds of being identified with a higher risk eGFR tests result in the study region. 


\begin{tabular}{|l|l|l|l|l|l|l|l|l|}
\hline & FBSL & HbA1c & TC & HDL & ACR & eGFR & BMI & Total \\
\hline Extracted & 193,680 & 73,885 & 194,816 & 182,237 & 50,790 & 244,166 & 192,455 & $1,132,029$ \\
\hline Missing data \\
\hline Test value & 1 & 0 & 0 & 0 & 0 & 0 & 0 & 1 \\
\hline Age & 1 & 1 & 1 & 1 & 0 & 2 & 1 & 7 \\
\hline Sex & 0 & 0 & 0 & 0 & 0 & 0 & 0 & 0 \\
\hline IRSD & 182 & 78 & 191 & 174 & 53 & 256 & 193 & 1,154 \\
\hline Excluded tests & 184 & 79 & 192 & 175 & 53 & 258 & 194 & 1,162 \\
\hline Included tests \\
\hline 7
\end{tabular}

Table 2. Table of excluded test data which had missing details. FBSL Fasting Blood Sugar Level, HbA1c Glycated Haemoglobin, TC Total Cholesterol, HDL High Density Lipoprotein, ACR Albumin Creatinine Ratio, $e G F R$ estimated Glomerular Filtration Rate, BMI Body Mass Index, IRSD Index of the Relative Socioeconomic Disadvantage, SA1 Statistical Area level 1.

\begin{tabular}{|c|c|c|c|c|c|c|c|c|}
\hline \multirow[b]{2}{*}{ CMRFs } & \multicolumn{2}{|l|}{ FBSL } & \multicolumn{2}{|l|}{ HbAlc } & \multicolumn{2}{|l|}{ TC } & \multicolumn{2}{|l|}{ HDL } \\
\hline & Total tests & $\begin{array}{l}\text { Higher risk }{ }^{\star} \text { results, } \\
\text { n (\%) }\end{array}$ & Total tests & $\begin{array}{l}\text { Higher risk* results, } \\
\text { n (\%) }\end{array}$ & Total tests & $\begin{array}{l}\text { Higher risk }{ }^{*} \text { results, } \\
\text { n (\%) }\end{array}$ & Total tests & $\begin{array}{l}\text { Higher risk* results, } \\
\text { n (\%) }\end{array}$ \\
\hline Rates & 193,496 & $16,259(8.4)$ & 73,806 & $7,920(10.73)$ & 194,624 & $57,506(29.55)$ & 182,062 & $21,238(11.67)$ \\
\hline \multicolumn{9}{|l|}{ Sex } \\
\hline Male & 83,603 & $9,279(4.8)$ & 35,757 & $4,444(6.02)$ & 90,950 & $23,503(12.0)$ & 85,266 & $15,872(8.72)$ \\
\hline Female & 109,893 & $6,980(3.6)$ & 38,049 & $3,476(4.71)$ & 103,674 & $34,003(17.47)$ & 96,796 & $5,366(2.95)$ \\
\hline \multicolumn{9}{|l|}{ Age (years) } \\
\hline $18-29$ & 19,747 & $238(0.1)$ & 3,480 & $250(0.34)$ & 14,247 & 2,127 (1.09) & 11,435 & $1,377(0.76)$ \\
\hline $30-39$ & 23,515 & $459(0.2)$ & 4,889 & $293(0.40)$ & 18,960 & $4,889(2.51)$ & 16,787 & $2,301(1.26)$ \\
\hline $40-49$ & 29,424 & $1,265(0.65)$ & 8,447 & $760(1.03)$ & 31,395 & $10,719(5.51)$ & 29,339 & 3,585 (1.97) \\
\hline $50-59$ & 37,085 & $2,948(1.52)$ & 13,510 & $1,507(2.04)$ & 39,663 & $16,316(8.38)$ & 37,824 & $4,283(2.35)$ \\
\hline $60-69$ & 37,962 & $4,670(2.41)$ & 17,665 & $2,064(2.80)$ & 40,471 & $13,620(7.00)$ & 39,134 & $4,227(2.32)$ \\
\hline $70-79$ & 29,009 & $4,396(2.27)$ & 15,715 & $1,860(2.52)$ & 31,186 & $6,748(3.47)$ & 30,114 & $3,419(1.88)$ \\
\hline $80+$ & 16,754 & $2,283(1.18)$ & 10,100 & $1,186(1.61)$ & 18,702 & 3,087 (1.59) & 17,429 & $2046(1.12)$ \\
\hline \multicolumn{9}{|l|}{ IRSD } \\
\hline Most D Q-1 & 38,885 & 4,495 (2.32) & 17,024 & 2,429 (3.29) & 39,347 & $10,631(5.46)$ & 36,625 & $5,520(3.03)$ \\
\hline Q-2 & 41,545 & $3,757(1.94)$ & 16,680 & $1,875(2.54)$ & 41,937 & $12,015(6.17)$ & 39,050 & $4,901(2.69)$ \\
\hline Q-3 & 39,828 & $3,386(1.75)$ & 15,376 & $1,585(2.15)$ & 40,401 & $12,045(6.19)$ & 37,794 & $4,201(2.31)$ \\
\hline Q-4 & 37,137 & $2,594(1.34)$ & 13,101 & $1,138(1.54)$ & 36,865 & $11,163(5.74)$ & 34,566 & $3,581(1.97)$ \\
\hline Least D Q-5 & 36,101 & $2027(1.05)$ & 11,625 & $893(1.21)$ & 36,074 & $11,652(5.99)$ & 34,027 & $3,035(1.67)$ \\
\hline
\end{tabular}

Table 3. Cross-tabulation of individual CMRFs (FBSL, HbA1c, TC and HDL) with the variables in study. FBSL Fasting Blood Sugar Level, HbA1c Glycated Haemoglobin, TC Total Cholesterol, HDL High Density Lipoprotein, Most D Most Disadvantaged, Least D Least Disadvantaged ${ }^{\star}$ Refer to Table 1 for high risk threshold levels of CMRFs.

The overall comparisons of model random effects are presented in Table 12. Reductions in the AIC values were observed among all CMRFs from the null model (M1) to the final model (M4) indicating a better fit for the final models. In the unadjusted null models, higher risk test results of eGFR demonstrated the most area-level variance (0.189) and TC the least (0.026). Adjusting the CMRFs for age and sex initially increased the $\tau^{2}$ of M2 for FBSL $(\mathrm{PCV}=+1.88 \%)$, HbAlc $(\mathrm{PCV}=+3.02 \%)$, HDL $(\mathrm{PCV}=+15.25 \%)$ and BMI $(\mathrm{PCV}=+1.48 \%)$. The $\tau^{2}$ was reduced in the final model among all CMRFs compared with the null models.

The Akaike Information Criterion (AIC) was used to evaluate model fit. The derived multilevel models were compared for: area-level variance $\left(\tau^{2}\right)$ at SA1 (level 2) level; proportional change in variance (PCV); Intra-cluster Correlation Coefficients (ICC); Median Odds Ratios (MORs); Area under the receiver operating characteristic (AUC) curve; and the change in AUC.

The ICCs of the unadjusted models ranged between $0.8 \%$ in high TC to $5.4 \%$ in low eGFR. Inclusion of IRSD after adjusting for age and sex had reduced the ICCs of all CMRFs in the final models, which ranged between $0.4 \%$ in low eGFR to $2.0 \%$ in obesity test results. The ICCs of the final models were low and suggest very limited area-level contextual effects. The AUC changes in model 2 and MORs of the final model support these findings. 


\begin{tabular}{|c|c|c|c|c|c|c|}
\hline \multirow[b]{2}{*}{ CMRFs } & \multicolumn{2}{|l|}{ ACR } & \multicolumn{2}{|l|}{ eGFR } & \multicolumn{2}{|l|}{ Obesity } \\
\hline & Total tests & $\begin{array}{l}\text { Higher risk* results, } \\
\text { n (\%) }\end{array}$ & Total tests & $\begin{array}{l}\text { Higher risk* results, } \\
\text { n (\%) }\end{array}$ & Total tests & $\begin{array}{l}\text { Higher risk }{ }^{*} \text { results, } \\
\text { n (\%) }\end{array}$ \\
\hline Rates & 50,737 & $2046(4.03)$ & 243,908 & $27,205(11.15)$ & 192,261 & $64,875(33.7)$ \\
\hline \multicolumn{7}{|l|}{ Sex } \\
\hline Male & 25,043 & $1,265(2.49)$ & 108,140 & $12,441(5.1)$ & 86,853 & $29,585(15.3)$ \\
\hline Female & 25,694 & $781(1.54)$ & 135,768 & $14,764(6.05)$ & 105,408 & $35,290(18.3)$ \\
\hline \multicolumn{7}{|l|}{ Age (years) } \\
\hline $18-29$ & 1546 & $47(0.09)$ & 32,961 & $72(0.03)$ & 23,277 & $4,582(2.38)$ \\
\hline $30-39$ & 2,278 & $71(0.14)$ & 29,047 & $105(0.04)$ & 22,799 & $6,535(3.40)$ \\
\hline $40-49$ & 4,870 & $108(0.21)$ & 35,778 & $330(0.14)$ & 30,401 & $10,595(5.51)$ \\
\hline $50-59$ & 9,272 & $230(0.45)$ & 42,695 & $1,112(0.46)$ & 37,285 & $13,825(7.19)$ \\
\hline $60-69$ & 13,388 & $412(0.81)$ & 43,423 & $3,626(1.49)$ & 38,370 & $15,310(7.96)$ \\
\hline $70-79$ & 12,337 & $605(1.19)$ & 34,406 & $8,507(3.49)$ & 30,074 & $11,324(5.89)$ \\
\hline $80+$ & 7,046 & $573(1.13)$ & 25,598 & $13,453(5.52)$ & 10,055 & $2,704(1.41)$ \\
\hline \multicolumn{7}{|l|}{ IRSD } \\
\hline Most D Q-1 & 11,915 & $638(1.26)$ & 49,288 & $7,061(2.89)$ & 37,476 & $15,365(7.99)$ \\
\hline $\mathrm{Q}-2$ & 11,350 & $485(0.96)$ & 52,947 & $6,354(2.61)$ & 40,172 & $14,334(7.46)$ \\
\hline Q-3 & 10,494 & $391(0.77)$ & 50,816 & $5,917(2.43)$ & 39,133 & $13,007(6.77)$ \\
\hline Q-4 & 8,732 & $308(0.61)$ & 46,440 & $4,406(1.81)$ & 37,370 & $11,766(6.12)$ \\
\hline Least D Q-5 & 8,246 & $224(0.44)$ & 44,417 & $3,467(1.42)$ & 38,110 & $10,403(5.41)$ \\
\hline
\end{tabular}

Table 4. Cross-tabulation of individual CMRFs (ACR, eGFR, and Obesity) with the variables in study. ACR Albumin Creatinine Ratio, eGFR estimated Glomerular Filtration Rate, BMI Body Mass Index, Most D Most Disadvantaged, Least $D$ Least Disadvantaged. ${ }^{\star}$ Refer to Table 1 for higher risk threshold levels of CMRFs.

Figure 2 provides a comparison of the ROC curves of the fitted models. Model $4 \mathrm{~s}$ (age + sex + IRSD adjusted models) and models $3 \mathrm{~s}$ (IRSD adjusted models) were chosen for the ROC curve plotting for comparative purpose. The predicted outcomes in the CMRFs plots are for the reference individual, i.e., individuals residing in the least disadvantaged areas (model 3) + female + age group 18-29 years (Model 4). A model curve closer to the top left corner of the subfigures indicate a better predictive accuracy of the model. The single measure summary of the ROC curves, AUCs of the final models ranged 0.62-0.88. The highest AUC value was observed for the final model of low eGFR. The AUC changes of model $2 \mathrm{~s}$ in relation to M0s ranged $0.01-0.08$, which reconfirm the contextual findings of ICCs that the general contextual effects observed in the models were minimal.

The proportions of the geographic variance in CMRFs contributed by IRSD were estimated through the PCV between M2 and M4. Adjusting the models for IRSD and individual-level variables explained a maximum $92.79 \%$ of the variance expressed by the null model of eGFR, reducing the ICC from 5.4 to $0.4 \%$. The changes were least among the adjusted models of TC, with a marginal reduction of ICC from $0.8 \%$ to $0.5 \%$. Thus, in the final models, the proportional reduction in variance was the largest for eGFR (PCV $=92.79 \%)$ and the least for TC $(\mathrm{PCV}=33.27 \%)$.

The identified specific contribution of IRSD in the geographic variation of CMRF was the highest among the geographic variance of higher risk findings of HDL tests (57.8\%), which was closely followed by FBSL (57.14\%); HbAlc (53.31\%); and ACR (51.17\%) test results. The contribution of IRSD was comparatively lower among the geographic variance of the higher risk findings of eGFR (41.75\%); BMI (41.06\%); and TC (14.71\%) test results, though not the least. Even though these specific proportions are large, it should be noted that it actually explained a lot of very little (i.e., variance of $0.01-0.07$ ).

\section{Discussion}

The study reports on the influence of areas on higher risk CMRF distribution and quantifies the specific proportion of geographic variance explained by IRSD. The work adds to the very few studies which consider multiple CMRF variables within the same region, or which are based on population derived data over extended years $^{16,17,20,29,31,32}$, and reports on both single and multilevel analyses ${ }^{38,55}$. The results present both the measures of association and area-level variance based on multilevel logistic regression analyses ${ }^{36}$. The findings of the study add to the existing evidence and discussion regarding the relevance of individual versus area-level interventions for the prevention and control of CMRFs.

We found consistent evidence for the association between area-level disadvantage and seven CMRFs among adult health service using residents of the Illawarra-Shoalhaven region in NSW Australia. In adjusted models, the odds of a higher risk finding increased with increase in area-level disadvantage among all CMRFs excepting TC, which showed an inverse pattern of association with increase in area-level disadvantage. Thus, in the final models we observed that, over and above individual age and sex, living in a disadvantaged neighbourhood proportionally increased the individual-level probability of being identified with a higher risk CMRF. The findings highlight the importance of including of area-level variables into health risk analyses. 


\begin{tabular}{|c|c|c|c|c|c|}
\hline & \multirow{2}{*}{\begin{tabular}{|l|} 
Single level model \\
Model 0
\end{tabular}} & \multicolumn{4}{|c|}{ Multilevel models } \\
\hline & & Model 1 & Model 2 & Model 3 & Model 4 \\
\hline Significance (LRT) & $* * *$ & $* * *$ & $* * *$ & $* * *$ & $* * *$ \\
\hline High FBSL & OR $(95 \% \mathrm{CI})$ & OR $(95 \% \mathrm{CI})$ & OR $(95 \%$ CI)OR ( $95 \%$ CI $)$ & OR $(95 \%$ CI) & OR $(95 \% \mathrm{CI})$ \\
\hline Intercept & $0.01(0.01-0.01)$ & $0.09(0.09-0.09)$ & $0.01(0.01-0.01)$ & $0.06(0.06-0.06)$ & $0.01(0.01-0.01)$ \\
\hline \multicolumn{6}{|l|}{ Sex } \\
\hline Female & Reference & & - & & \\
\hline Male & $1.62(1.56-1.67)$ & & $1.63(1.56-1.7)$ & & $1.63(1.58-1.7)$ \\
\hline \multicolumn{6}{|l|}{ Age } \\
\hline $18-29$ & Reference & & - & & $1.64(1.41-1.9)$ \\
\hline $30-39$ & $1.60(1.36-1.87)$ & & $1.63(1.39-1.9)$ & & $3.58(3.12-4.1)$ \\
\hline $40-49$ & $3.41(2.97-3.93)$ & & $3.53(3.07-4.1)$ & & $6.81(5.98-7.8)$ \\
\hline $50-59$ & $6.48(5.68-7.42)$ & & $6.77(5.93-7.7)$ & & $11.05(9.71-12.6)$ \\
\hline $60-69$ & $10.48(9.21-11.98)$ & & $11.07(9.72-12.6)$ & & $13.74(12.07-15.6)$ \\
\hline $70-79$ & $13.35(11.73-15.27)$ & & $13.93(12.22-15.9)$ & & $12.02(10.52-13.7)$ \\
\hline $80+$ & $12.01(10.51-13.78)$ & & $12.33(10.79-14.1)$ & & \\
\hline \multicolumn{6}{|l|}{ IRSD } \\
\hline Q-5 & & & & Reference & - \\
\hline Q-4 & & & & $1.27(1.18-1.36)$ & $1.27(1.18-1.37)$ \\
\hline Q-3 & & & & $1.58(1.47-1.69)$ & $1.49(1.39-1.61)$ \\
\hline Q-2 & & & & $1.68(1.57-1.80)$ & $1.62(1.50-1.74)$ \\
\hline Most D Q-1 & & & & $2.20(2.06-2.36)$ & $2.11(1.96-2.26)$ \\
\hline AIC & 103,645 & $111,022.8$ & $103,066.2$ & $110,552.5$ & $102,689.6$ \\
\hline Variance & & 0.101 & 0.103 & 0.034 & 0.044 \\
\hline PCV & & - & $+1.88 \%$ & $-66.41 \%$ & $-56.33 \%$ \\
\hline ICC (\%) & & 3.00 & 3.00 & 1.0 & 1.3 \\
\hline MOR & & 1.35 & 1.36 & 1.19 & 1.22 \\
\hline AUC & 0.70 & 0.61 & 0.73 & 0.60 & 0.72 \\
\hline AUC change $^{\dagger}$ & & & +0.03 & & \\
\hline
\end{tabular}

Table 5. Single and multilevel logistic regression model summaries for high FBSL (FBSL $\geq 7.0 \mathrm{mmol} / \mathrm{L}$ ). ${ }^{* * *} p<0.001$; ${ }^{\dagger}$ Change in Model 2 in relation to Model 0; Model 0-Single level model adjusted for age + sex; Model 1-null model at SA1 level; Model 2-M1 + individual-level: age + sex; Model 3-Model $1+$ Area level: IRSD quintiles of SA1s; Model 4-Model $1+$ Model $2+$ Model 3.

The ICCs of CMRFs in all the models were comparatively small (Table 12) in all the models. In the fully adjusted models, the ICCs were further reduced and ranged between $0.4 \%$ and $2.0 \%$ in low eGFR and BMI respectively. As per the interpretation framework proposed by Merlo et al., an ICC value less than 10\% is indicative of very little geographic difference ${ }^{56}$. The AUC change of the model $2 \mathrm{~s}$ in relation to the single level models (range 0.01-0.08) reconfirm on these findings. However, this has to be interpreted along with the traditional geographic comparisons such as the proportion of the individuals who are affected with higher risk CMRF outcomes. Therefore, a small geographic difference with uniformly higher, medium, or lower proportion of affected individuals indicates homogeneity of the higher risk CMRF findings within their geographic units ${ }^{56}$. Such a situation would call for balanced universal approaches to prevent and control the higher risk CMRFs, with a proportional focus to the need and disadvantage level of affected populations $s^{57,58}$. However, it is also worth noting that when the exposure to an agent is homogenic in a community, the traditional epidemiological methods are not very helpful in identifying their markers of susceptibility ${ }^{59}$.

Our results confirm, and are comparable with, associations between area-level disadvantage and CMRFs reported in previous studies ${ }^{3-23}$, and extends their findings. The results primarily confirm the geographic variation of CMRFs and associations with area level disadvantage, as reported in previous studies. Further, the study provides means to compare this association which were observed consistently with a range of multiple CMRFs analysed in this study. The study extends on previous reports by differentiating the individual and area-level contributors to the exhibited geographic variance of CMRFs. And most importantly, the general contextual effect and the specific contributions of IRSD on the geographic variance of multiple CMRFs were identified, which is unique in the literature and highly informative for health care service commissioning.

The TC test results often stood apart from the major findings of this study, demonstrating inverse associations with IRSD. However, this was not reflected in the HDL findings, even though both are components of the lipid profile in an individual. This raises the possibility of a medication effect on TC in these areas, where the lipid lowering drugs have a less consistent effect in raising HDL than in lowering $\mathrm{TC}^{60}$. Other factors associated with the higher risk HDL test results may include uncontrolled diabetes ${ }^{61,}$ smoking ${ }^{62}$, sedentary life style ${ }^{63,64}$, obesity ${ }^{65}$, 


\begin{tabular}{|c|c|c|c|c|c|}
\hline & \multirow{2}{*}{\begin{tabular}{|l|} 
Single level model \\
Model 0
\end{tabular}} & \multicolumn{4}{|c|}{ Multilevel models } \\
\hline & & Model 1 & Model 2 & Model 3 & Model 4 \\
\hline Significance (LRT) & $* * *$ & $* * *$ & $* * *$ & $* * *$ & $* * *$ \\
\hline High HbAlc & OR $(95 \% \mathrm{CI})$ & OR (95\% CI) & OR $(95 \% \mathrm{CI})$ & OR $(95 \% \mathrm{CI})$ & OR (95\% CI) \\
\hline Intercept & $0.07(0.06-0.08)$ & $0.12(0.12-0.12)$ & $0.07(0.06-0.07)$ & $0.08(0.08-0.09)$ & $0.05(0.04-0.05)$ \\
\hline \multicolumn{6}{|l|}{ Sex } \\
\hline Female & Reference & & - & & - \\
\hline Male & $1.37(1.31-1.43)$ & & $1.38(1.32-1.45)$ & & $1.39(1.32-1.45)$ \\
\hline \multicolumn{6}{|l|}{ Age } \\
\hline $18-29$ & Reference & & - & & - \\
\hline $30-39$ & $0.81(0.68-0.96)$ & & $0.81(0.68-0.96)$ & & $0.81(0.68-0.96)$ \\
\hline $40-49$ & $1.22(1.06-1.42)$ & & $1.24(1.07-1.44)$ & & $1.26(1.08-1.46)$ \\
\hline 50-59 & $1.53(1.34-1.77)$ & & $1.56(1.36-1.80)$ & & $1.57(1.36-1.81)$ \\
\hline $60-69$ & $1.61(1.40-1.85)$ & & $1.64(1.43-1.88)$ & & $1.64(1.43-1.88)$ \\
\hline $70-79$ & $1.63(1.42-1.87)$ & & $1.64(1.42-1.88)$ & & $1.62(1.41-1.86)$ \\
\hline $80+$ & $1.64(1.43-1.90)$ & & $1.63(1.41-1.88)$ & & $1.60(1.39-1.85)$ \\
\hline \multicolumn{6}{|l|}{ IRSD } \\
\hline Q-5 & & & & Reference & - \\
\hline $\mathrm{Q}-4$ & & & & $0.08(0.08-0.09)$ & $1.15(1.04-1.28)$ \\
\hline Q-3 & & & & $1.14(1.03-1.27)$ & $1.39(1.26-1.54)$ \\
\hline $\mathrm{Q}-2$ & & & & $1.40(1.27-1.54)$ & $1.55(1.41-1.71)$ \\
\hline Most D Q-1 & & & & $1.54(1.40-1.69)$ & $2.02(1.84-2.22)$ \\
\hline AIC & 49,897 & $50,114.5$ & $49,690.2$ & $49,875.3$ & $49,453.3$ \\
\hline Variance & & 0.103 & 0.106 & \begin{tabular}{|l|}
0.047 \\
\end{tabular} & \begin{tabular}{|l|l|}
0.049 \\
\end{tabular} \\
\hline PCV & & - & $+3.02 \%$ & $-54.82 \%$ & $-51.91 \%$ \\
\hline ICC (\%) & & 3.0 & 3.1 & 1.4 & 1.5 \\
\hline MOR & & 1.36 & 1.36 & 1.23 & 1.24 \\
\hline AUC & 0.56 & 0.63 & 0.64 & 0.61 & 0.63 \\
\hline AUC change $\dagger$ & & & +0.08 & & \\
\hline
\end{tabular}

Table 6. Single and multilevel logistic regression model summaries for high HbAlc (HbA1c $>7.5 \%)$. ${ }^{* * *} p<0.001$; ${ }^{\dagger}$ Change in Model 2 in relation to Model 0; Model 0-Single level model adjusted for age + sex; Model 1-null model at SA1 level; Model 2-Model 1+individual-level: age + sex; Model 3-Model 1+ Area level: IRSD quintiles of SA1s; Model 4-Model 1+ Model $2+$ Model 3.

and poor diet quality ${ }^{66,67}$. However the reason for the inverse association demonstrated by TC test results are not clearly established within the current study results and requires further research to explore possible individual and area-level contributions.

The study has to be considered within its limitations. Primarily, the cross sectional nature of analyses adopted in this study do not yield support for any causal relationships. In addition, the non-linear and time varying effects of covariates analysed in this study restrict generalisability of their findings though very informative for regional health care service commissioning. Secondly, the IRSD quintiles included as the key explanatory variable represent relative disadvantage in an area and have limitations intrinsic to aggregate measures. Thirdly, it should be noted that the data used in this study are extracted from people already utilising the health care service facilities in the area. Fourthly, the readers should be mindful that the variance reported in this study are attributable to (1) individual level factors (age, sex) analysed at the area-level, (2) area-level contextual influences (IRSD), and (3) other individual and area-level characteristics not considered in this study. However, further individual-level data extractions or collections are not possible with this study's dataset as the de-identification process precludes the inclusion of any further individual level data. Other individual and area-level factors not considered in this study could include: individual-level SES ${ }^{68}$, type of neighbourhood food outlets ${ }^{69-72}$, poor physical activity resources $^{73,74}$, residential density and service availability ${ }^{75}$. Finally, the assumptions of the standard multilevel logistic regression modelling methods adopted in this study would not be able to account for the autocorrelation of the area-level residuals (if any) of the models. Expected shortcomings due to this could be an overestimation of random effects in our models ${ }^{76}$. However, any such effects were observed to be very marginal in our results as the random effect estimates are already at their lower limits. While acknowledging this limitation, we believe the effects of this are not critical in our results. Hybrid models which provide more precise estimates of random effects are becoming increasingly available with advances in computational technologies ${ }^{77}$. However, they 


\begin{tabular}{|c|c|c|c|c|c|}
\hline & \multirow{2}{*}{$\begin{array}{l}\text { Single level model } \\
\text { Model } 0\end{array}$} & \multicolumn{4}{|l|}{ Multilevel models } \\
\hline & & Model 1 & \begin{tabular}{|l|} 
Model 2 \\
\end{tabular} & Model 3 & Model 4 \\
\hline Significance (LRT) & $* * *$ & $* * *$ & $* * *$ & $* * *$ & $* * *$ \\
\hline High TC & OR $(95 \% \mathrm{CI})$ & OR $(95 \% \mathrm{CI})$ & OR $(95 \% \mathrm{CI})$ & OR $(95 \% \mathrm{CI})$ & OR $(95 \% \mathrm{CI})$ \\
\hline Intercept & $0.20(0.19-0.21)$ & $0.42(0.42-0.42)$ & $0.20(0.19-0.21)$ & $0.08(0.08-0.09)$ & $0.22(0.21-0.23)$ \\
\hline \multicolumn{6}{|l|}{ Sex } \\
\hline Female & Reference & & - & & - \\
\hline Male & $0.69(0.68-0.71)$ & & $0.69(0.68-0.71)$ & & $0.69(0.68-0.71)$ \\
\hline \multicolumn{6}{|l|}{ Age } \\
\hline $18-29$ & Reference & & - & & - \\
\hline $30-39$ & $2.01(1.90-2.13)$ & & $2.02(1.91-2.14)$ & & $2.01(1.90-2.13)$ \\
\hline $40-49$ & $3.01(2.86-3.17)$ & & $3.01(2.86-3.17)$ & & $3.00(2.85-3.16)$ \\
\hline $50-59$ & $4.09(3.89-4.30)$ & & $4.08(3.88-4.29)$ & & $4.07(3.87-4.28)$ \\
\hline $60-69$ & $2.97(2.83-3.13)$ & & $2.95(2.80-3.10)$ & & $2.95(2.80-3.10)$ \\
\hline $70-79$ & $1.61(1.53-1.70)$ & & $1.60(1.52-1.69)$ & & $1.61(1.52-1.70)$ \\
\hline $80+$ & $1.14(1.07-1.21)$ & & $1.13(1.07-1.20)$ & & $1.14(1.07-1.21)$ \\
\hline \multicolumn{6}{|l|}{ IRSD } \\
\hline Q-5 & & & & Reference & - \\
\hline Q-4 & & & & $0.91(0.87-0.95)$ & $0.94(0.90-0.98)$ \\
\hline Q-3 & & & & $0.88(0.85-0.92)$ & $0.94(0.90-0.98)$ \\
\hline Q-2 & & & & $0.84(0.80-0.87)$ & $0.90(0.87-0.94)$ \\
\hline Most D Q-1 & & & & $0.77(0.74-0.81)$ & $0.84(0.81-0.88)$ \\
\hline AIC & 227,464 & $235,931.6$ & $227,254.6$ & $235,795.4$ & $227,199.2$ \\
\hline Variance & & 0.026 & 0.020 & \begin{tabular}{|l|}
0.018 \\
\end{tabular} & 0.017 \\
\hline PCV & & - & $-21.76 \%$ & $-27.81 \%$ & $-33.27 \%$ \\
\hline ICC (\%) & & 0.8 & 0.6 & \begin{tabular}{|l|}
0.6 \\
\end{tabular} & 0.5 \\
\hline MOR & & 1.16 & 1.14 & 1.14 & 1.13 \\
\hline AUC & 0.63 & 0.56 & 0.64 & 0.56 & 0.64 \\
\hline AUC change $^{\dagger}$ & & & +0.01 & & \\
\hline \multicolumn{6}{|c|}{ Proportional variance explained by IRSD: $14.71 \%$} \\
\hline
\end{tabular}

Table 7. Single and multilevel logistic regression model summaries for high TC (TC $\geq 5.5 \mathrm{mmol} / \mathrm{L})$. ${ }^{* * *} p<0.001$; ${ }^{\dagger}$ Change in Model 2 in relation to Model 0; Model 0-Single level model adjusted for age + sex; Model 1-null model at SA1 level; Model 2-M1 + individual-level: age + sex; Model 3-Model $1+$ Area level: IRSD quintiles of SA1s; Model 4-Model $1+$ Model $2+$ Model 3.

would not be directly applicable to our data sets, mainly due to the non-availability of location specific data at individual-level in our study data.

Notwithstanding these limitations, the study is unique in that it analysed a range of CMRFs across a widely dispersed population and included both rural and urban residents. In addition, the study used six years (year 2012-2017) of CMRF tests data from the region in the hierarchical multilevel analyses. The findings of the study indicate that those residing in the most disadvantaged areas are more likely to be identified with higher risk CMRFs than those in lower disadvantage areas. However, the low ICC, AUC change and MOR values of the area-level models do not support for contextual approaches. Rather, the findings of the study support a proportionate universalism approach in which health resources are made universally available but proportional to the need and disadvantage level of the affected population ${ }^{57,58}$.

\section{Conclusion}

The study demonstrates that in the Illawarra Shoalhaven region of Australia, people residing in socioeconomically disadvantaged areas have a higher probability of being identified with higher risk CMRFs across a range of factors. The low general contextual effects of the areas suggest for universal intervention for the prevention and control of CMRFs in this study region, but proportional to the need and disadvantage level. The patterns were consistent across the six CMRFs analysed in this study; and comparable with similar studies reported nationally and globally. Based on our findings, we recommend further area-level research to discern the role of other contextual factors not analysed in this study especially the area-level access to health care services to determine its existing role and adequacy ${ }^{78}$, and evidence based universal interventions for the prevention and control of CMRFs but proportionate to the priority level of the populations based on area-level disadvantage. 


\begin{tabular}{|c|c|c|c|c|c|}
\hline & \multirow{2}{*}{\begin{tabular}{|l} 
Single level model \\
Model 0
\end{tabular}} & \multicolumn{4}{|c|}{ Multilevel models } \\
\hline & & Model 1 & Model 2 & Model 3 & Model 4 \\
\hline Significance (LRT) & $* * *$ & $* * *$ & $* * *$ & $* * *$ & $* * *$ \\
\hline Low HDL & OR $(95 \%$ CI $)$ & OR $(95 \% \mathrm{CI})$ & OR $(95 \% \mathrm{CI})$ & OR $(95 \%$ CI $)$ & OR $(95 \%$ CI $)$ \\
\hline Intercept & $0.06(0.06-0.07)$ & $0.13(0.13-0.13)$ & $0.06(0.06-0.07)$ & $0.10(0.09-0.10)$ & $0.05(0.04-0.05)$ \\
\hline \multicolumn{6}{|l|}{ Sex } \\
\hline Female & Reference & & - & & - \\
\hline Male & $3.92(3.80-4.05)$ & & $3.98(3.85-4.11)$ & & $3.98(3.85-4.11)$ \\
\hline \multicolumn{6}{|l|}{ Age } \\
\hline $18-29$ & Reference & & - & & - \\
\hline $30-39$ & $1.11(1.03-1.20)$ & & $1.11(1.03-1.20)$ & & $1.12(1.04-1.21)$ \\
\hline $40-49$ & $0.97(0.91-1.04)$ & & $0.99(0.92-1.05)$ & & $1.00(0.93-1.07)$ \\
\hline $50-59$ & $0.87(0.81-0.93)$ & & $0.88(0.82-0.94)$ & & $0.89(0.83-0.95)$ \\
\hline $60-69$ & $0.81(0.76-0.87)$ & & $0.82(0.77-0.88)$ & & $0.82(0.77-0.88)$ \\
\hline $70-79$ & $0.85(0.80-0.91)$ & & $0.86(0.80-0.92)$ & & $0.85(0.79-0.91)$ \\
\hline $80+$ & $0.94(0.87-1.01)$ & & $0.93(0.86-1.00)$ & & $0.91(0.85-0.98)$ \\
\hline \multicolumn{6}{|l|}{ IRSD } \\
\hline Q-5 & & & & Reference & - \\
\hline Q-4 & & & & $1.18(1.11-1.26)$ & $1.20(1.13-1.28)$ \\
\hline Q-3 & & & & $1.29(1.21-1.37)$ & $1.32(1.24-1.41)$ \\
\hline Q-2 & & & & $1.48(1.39-1.57)$ & $1.51(1.42-1.61)$ \\
\hline Most D Q-1 & & & & $1.81(1.71-1.92)$ & $1.90(1.78-2.02)$ \\
\hline AIC & 123,277 & $130,649.7$ & $122,700.0$ & $130,294.3$ & $122,328.3$ \\
\hline Variance & & 0.071 & 0.081 & 0.030 & 0.034 \\
\hline PCV & & - & $+15.25 \%$ & $-58.05 \%$ & $-51.37 \%$ \\
\hline ICC (\%) & & 2.1 & 2.4 & 0.9 & 1.0 \\
\hline MOR & & 1.29 & 1.31 & 1.18 & 1.19 \\
\hline AUC & 0.67 & 0.60 & 0.71 & 0.59 & 0.70 \\
\hline AUC change $^{\dagger}$ & & & +0.04 & & \\
\hline
\end{tabular}

Table 8. Single and multilevel logistic regression model summaries for low HDL $(\mathrm{HDL}<1 \mathrm{mmol} / \mathrm{L})$. ${ }^{* * *} p<0.001 ;{ }^{\dagger}$ Change in Model 2 in relation to Model 0; Model 0-Single level model adjusted for age + sex; Model 1-null model at SA1 level; Model 2-M1 + individual-level: age + sex; Model 3-Model $1+$ Area level: IRSD quintiles of SA1s; Model 4-Model 1+ Model $2+$ Model 3. 


\begin{tabular}{|c|c|c|c|c|c|}
\hline & \multirow{2}{*}{$\begin{array}{l}\text { Single level model } \\
\text { Model } 0\end{array}$} & \multicolumn{4}{|c|}{ Multilevel models } \\
\hline & & Model 1 & Model 2 & Model 3 & Model 4 \\
\hline Significance (LRT) & $* * *$ & $* * *$ & $* * *$ & $* * *$ & $* * *$ \\
\hline High ACR & OR $(95 \% \mathrm{CI})$ & OR $(95 \% \mathrm{CI})$ & OR $(95 \% \mathrm{CI})$ & OR $(95 \% \mathrm{CI})$ & OR (95\% CI) \\
\hline Intercept & $0.02(0.02-0.03)$ & $0.04(0.04-0.04)$ & $0.02(0.02-0.03)$ & $0.03(0.02-0.03)$ & $0.02(0.01-0.02)$ \\
\hline \multicolumn{6}{|l|}{ Sex } \\
\hline Female & Reference & - & - & & - \\
\hline Male & $1.74(1.59-1.91)$ & & $1.75(1.59-1.92)$ & & $1.76(1.60-1.93)$ \\
\hline \multicolumn{6}{|l|}{ Age } \\
\hline $18-29$ & Reference & & - & & - \\
\hline $30-39$ & $0.99(0.69-1.45)$ & & $1.00(0.69-1.45)$ & & $0.99(0.68-1.44)$ \\
\hline $40-49$ & $0.68(0.49-0.98)$ & & $0.69(0.49-0.97)$ & & $0.70(0.49-0.98)$ \\
\hline $50-59$ & $0.76(0.56-1.06)$ & & $0.77(0.56-1.05)$ & & $0.77(0.56-1.05)$ \\
\hline $60-69$ & $0.95(0.70-1.30)$ & & $0.95(0.70-1.30)$ & & $0.95(0.70-1.29)$ \\
\hline 70-79 & $1.54(1.15-2.11)$ & & $1.55(1.14-2.09)$ & & $1.52(1.12-2.05)$ \\
\hline $80+$ & $2.73(2.04-3.74)$ & & $2.74(2.02-3.71)$ & & $2.65(1.96-3.59)$ \\
\hline \multicolumn{6}{|l|}{ IRSD } \\
\hline Q-5 & & & & Reference & - \\
\hline $\mathrm{Q}-4$ & & & & $1.31(1.10-1.57)$ & $1.25(1.04-1.50)$ \\
\hline Q-3 & & & & $1.39(1.16-1.65)$ & $1.27(1.06-1.51)$ \\
\hline $\mathrm{Q}-2$ & & & & $1.61(1.36-1.90)$ & $1.45(1.23-1.72)$ \\
\hline Most D Q-1 & & & & $2.02(1.72-2.38)$ & $1.84(1.56-2.16)$ \\
\hline AIC & 16,596 & $17,130.0$ & $16,585.2$ & $17,053.0$ & $16,527.2$ \\
\hline Variance & & 0.092 & 0.073 & 0.044 & 0.036 \\
\hline PCV & & - & $-20.53 \%$ & $-52.88 \%$ & $-61.19 \%$ \\
\hline ICC (\%) & & 2.7 & 2.2 & 1.3 & 1.1 \\
\hline MOR & & 1.34 & 1.30 & 1.22 & 1.20 \\
\hline AUC & 0.65 & 0.70 & 0.69 & 0.62 & 0.67 \\
\hline AUC change $\dagger$ & & & +0.04 & & \\
\hline
\end{tabular}

Table 9. Single and multilevel logistic regression model summaries for high ACR (ACR $\geq 30 \mathrm{mcg} / \mathrm{L}$ to $\mathrm{mg} / \mathrm{L}$ ). ${ }^{* * *} p<0.001$; ${ }^{\dagger}$ Change in Model 2 in relation to Model 0; Model 0-Single level model adjusted for age + sex; Model 1-null model at SA1 level; Model 2-M1 + individual-level: age + sex; Model 3-Model $1+$ Area level: IRSD quintiles of SA1s; Model 4-Model 1+ Model $2+$ Model 3. 


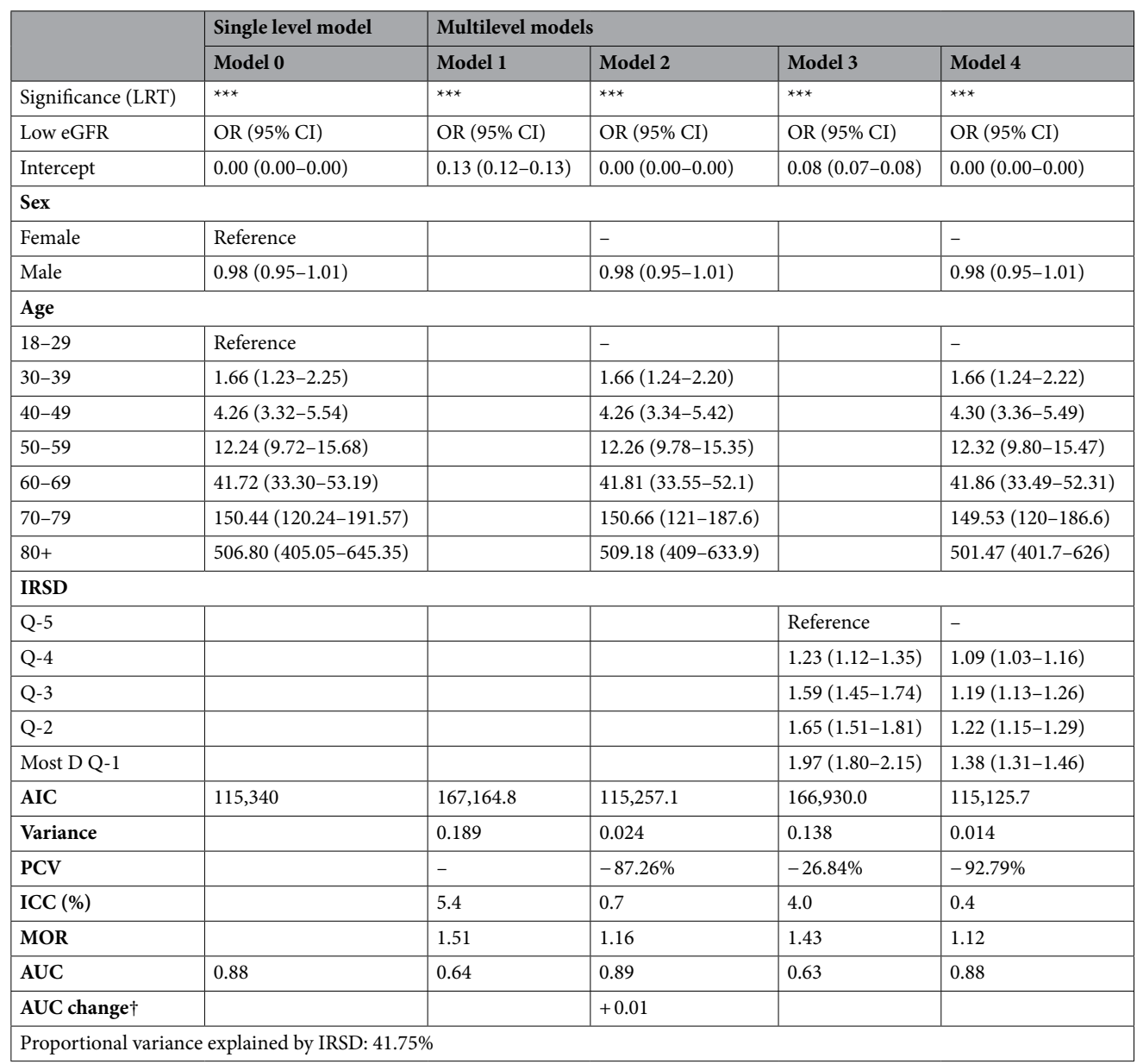

Table 10. Single and multilevel logistic regression model summaries for low eGFR (eGFR $<60 \mathrm{~mL} /$ $\left.\min / 1.73 \mathrm{~m}^{2}\right) .{ }^{* * *} p<0.001 ;{ }^{\dagger}$ Change in Model 2 in relation to Model 0; Model 0-Single level model adjusted for age + sex; Model 1-null model at SA1 level; Model 2-M1 + individual-level: age + sex; Model 3-Model $1+$ Area level: IRSD quintiles of SA1s; Model 4-Model 1+Model $2+$ Model 3. 


\begin{tabular}{|c|c|c|c|c|c|}
\hline & \multirow{2}{*}{$\begin{array}{l}\text { Single level model } \\
\text { Model } 0\end{array}$} & \multicolumn{4}{|c|}{ Multilevel models } \\
\hline & & Model 1 & Model 2 & Model 3 & Model 4 \\
\hline Significance (LRT) & $* * *$ & $* * *$ & $* * *$ & $* * *$ & $* * *$ \\
\hline Obesity & OR $(95 \%$ CI $)$ & OR $(95 \% \mathrm{CI})$ & OR $(95 \% \mathrm{CI})$ & OR $(95 \% \mathrm{CI})$ & OR $(95 \% \mathrm{CI})$ \\
\hline Intercept & $0.25(0.24-0.25)$ & $0.51(0.50-0.51)$ & $0.25(0.24-0.26)$ & $0.37(0.35-0.39)$ & $0.18(0.17-0.19)$ \\
\hline \multicolumn{6}{|l|}{ Sex } \\
\hline Female & Reference & & - & & - \\
\hline Male & $0.99(0.97-1.00)$ & & $0.99(0.97-1.01)$ & & $0.99(0.97-1.01)$ \\
\hline \multicolumn{6}{|l|}{ Age } \\
\hline $18-29$ & Reference & & - & & - \\
\hline $30-39$ & $1.64(1.57-1.71)$ & & $1.63(1.56-1.71)$ & & $1.64(1.57-1.71)$ \\
\hline $40-49$ & $2.18(2.10-2.27)$ & & $2.20(2.11-2.29)$ & & $2.21(2.12-2.30)$ \\
\hline $50-59$ & $2.41(2.32-2.50)$ & & $2.44(2.34-2.53)$ & & $2.44(2.35-2.54)$ \\
\hline $60-69$ & $2.71(2.61-2.82)$ & & $2.73(2.63-2.84)$ & & $2.74(2.63-2.84)$ \\
\hline 70-79 & $2.47(2.37-2.57)$ & & $2.44(2.34-2.54)$ & & $2.43(2.33-2.53)$ \\
\hline $80+$ & $1.50(1.42-1.59)$ & & $1.46(1.38-1.55)$ & & $1.45(1.37-1.53)$ \\
\hline \multicolumn{6}{|l|}{ IRSD } \\
\hline Q-5 & & & & Reference & - \\
\hline $\mathrm{Q}-4$ & & & & $1.25(1.17-1.33)$ & $1.26(1.18-1.34)$ \\
\hline Q-3 & & & & $1.37(1.29-1.46)$ & $1.38(1.30-1.47)$ \\
\hline $\mathrm{Q}-2$ & & & & $1.51(1.42-1.61)$ & $1.54(1.44-1.64)$ \\
\hline Most D Q-1 & & & & $1.90(1.79-2.03)$ & $1.94(1.83-2.07)$ \\
\hline AIC & 242,064 & $242,793.2$ & $239,122.6$ & $242,443.7$ & $238,748.4$ \\
\hline Variance & & 0.115 & 0.117 & 0.071 & 0.069 \\
\hline PCV & & - & $+1.48 \%$ & $-38.76 \%$ & $-40.30 \%$ \\
\hline ICC (\%) & & 3.4 & 3.4 & 2.1 & 2.0 \\
\hline MOR & & 1.38 & 1.39 & 1.29 & 1.28 \\
\hline AUC & 0.56 & 0.60 & 0.63 & 0.60 & 0.62 \\
\hline AUC change $^{\dagger}$ & & & +0.07 & & \\
\hline
\end{tabular}

Table 11. Single and multilevel logistic regression model summaries for obesity $\left(B M I \geq 30 \mathrm{~kg} / \mathrm{m}^{2}\right)$. ${ }^{* *} p<0.001 ;{ }^{\dagger}$ Change in Model 2 in relation to Model 0; Model 0-Single level model adjusted for age + sex; Model 1-Single level model adjusted for age + sex; Model 1-null model at SA1 level; Model 2M1 + individual-level: age + sex; Model 3-Model 1 + Area level: IRSD quintiles of SA1s; Model 4-Model $1+$ Model $2+$ Model 3 . 


\begin{tabular}{|c|c|c|c|c|c|c|c|}
\hline & FBSL & HbA1c & TC & HDL & ACR & eGFR & Obesity \\
\hline \multicolumn{8}{|c|}{ Model 0: Single level model, adjusted for age and sex } \\
\hline AIC & 103,645 & 49,897 & 227,464 & 123,277 & 16,596 & 115,340 & 242,064 \\
\hline AUC & 0.70 & 0.56 & 0.63 & 0.67 & 0.65 & 0.88 & 0.56 \\
\hline \multicolumn{8}{|c|}{ Model 1: Null Model, at level 1} \\
\hline AIC & $111,022.8$ & $50,114.5$ & $235,931.6$ & $130,649.7$ & $17,130.0$ & $167,164.8$ & $242,793.2$ \\
\hline$\tau^{2}$ & 0.101 & 0.103 & 0.026 & 0.071 & 0.092 & 0.189 & 0.115 \\
\hline ICC (\%) & 3.0 & 3.0 & 0.8 & 2.1 & 2.7 & 5.4 & 3.4 \\
\hline MOR & 1.35 & 1.36 & 1.16 & 1.29 & 1.34 & 1.51 & 1.38 \\
\hline AUC & 0.61 & 0.63 & 0.56 & 0.60 & 0.70 & 0.64 & 0.60 \\
\hline \multicolumn{8}{|c|}{ Model 2: Age and sex adjusted model, at level 1} \\
\hline AIC & $103,066.2$ & $49,690.2$ & $227,254.6$ & $122,700.0$ & $16,585.2$ & $115,257.1$ & $239,122.6$ \\
\hline$\tau^{2}$ & 0.103 & 0.106 & 0.020 & 0.081 & 0.073 & 0.024 & 0.117 \\
\hline ICC (\%) & 3.0 & 3.1 & 0.6 & 2.4 & 2.2 & 0.7 & 3.4 \\
\hline MOR & 1.36 & 1.36 & 1.14 & 1.31 & 1.30 & 1.16 & 1.39 \\
\hline AUC & 0.73 & 0.64 & 0.64 & 0.71 & 0.69 & 0.89 & 0.63 \\
\hline AUC change $\dagger$ & +0.03 & +0.08 & +0.01 & +0.04 & +0.04 & +0.01 & +0.07 \\
\hline PCV & $+1.88 \%$ & $+3.02 \%$ & $-21.76 \%$ & $+15.25 \%$ & $-20.53 \%$ & $-87.26 \%$ & $+1.48 \%$ \\
\hline \multicolumn{8}{|c|}{ Model 3: IRSD adjusted model, at level 1} \\
\hline AIC & $110,552.5$ & $49,875.3$ & $235,795.4$ & $130,294.3$ & $17,053.0$ & $166,930.0$ & $242,443.7$ \\
\hline$\tau^{2}$ & 0.034 & 0.047 & 0.018 & 0.030 & 0.044 & 0.138 & 0.071 \\
\hline ICC (\%) & 1.0 & 1.4 & 0.6 & 0.9 & 1.3 & 4.0 & 2.1 \\
\hline MOR & 1.19 & 1.23 & 1.14 & 1.18 & 1.22 & 1.43 & 1.29 \\
\hline AUC & 0.60 & 0.61 & 0.56 & 0.59 & 0.62 & 0.63 & 0.60 \\
\hline PCV & $-66.41 \%$ & $-54.82 \%$ & $-27.81 \%$ & $-58.05 \%$ & $-52.88 \%$ & $-26.84 \%$ & $-38.76 \%$ \\
\hline \multicolumn{8}{|c|}{ Model 4: Age, sex and IRSD adjusted final model, at level 1} \\
\hline AIC & $102,689.6$ & $49,453.3$ & $227,199.2$ & $122,328.3$ & $16,527.2$ & $115,125.7$ & $238,748.4$ \\
\hline$\tau^{2}$ & 0.044 & 0.049 & 0.017 & 0.034 & 0.036 & 0.014 & 0.069 \\
\hline ICC (\%) & 1.3 & 1.5 & 0.5 & 1.0 & 1.1 & 0.4 & 2.0 \\
\hline MOR & 1.22 & 1.24 & 1.13 & 1.19 & 1.20 & 1.12 & 1.28 \\
\hline AUC & 0.72 & 0.63 & 0.64 & 0.70 & 0.67 & 0.88 & \begin{tabular}{|l|}
0.62 \\
\end{tabular} \\
\hline PCV & $-56.33 \%$ & $-51.91 \%$ & $-33.27 \%$ & $-51.37 \%$ & $-61.19 \%$ & $-92.79 \%$ & $-40.30 \%$ \\
\hline
\end{tabular}

Table 12. Summary model fit values and comparison of the multilevel models. ${ }^{\dagger}$ Change in relation to M0; $\tau^{2}$-Variance; AIC-Akaike Information Criterion; AUC-Area under the receiver operating characteristic curve; ICC-Intra-cluster Correlation Coefficients; MOR-Median Odds Ratios; PCV_proportional change in variance (in relation to Model $1 \mathrm{~s}$ ). 


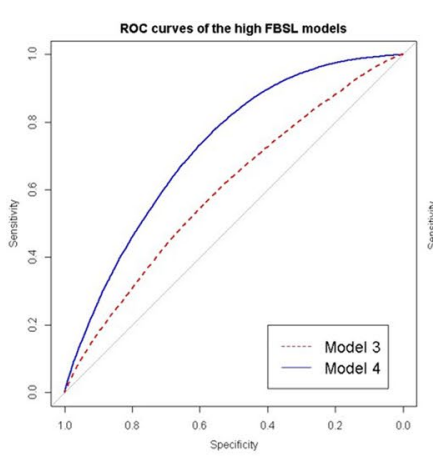

(a)

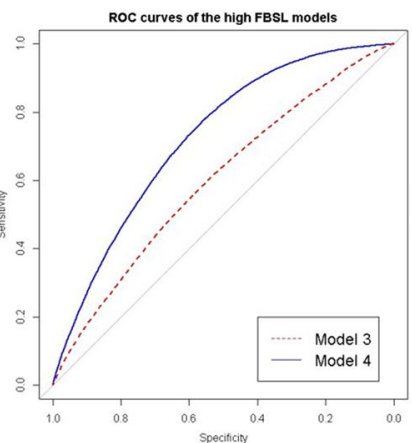

(b)

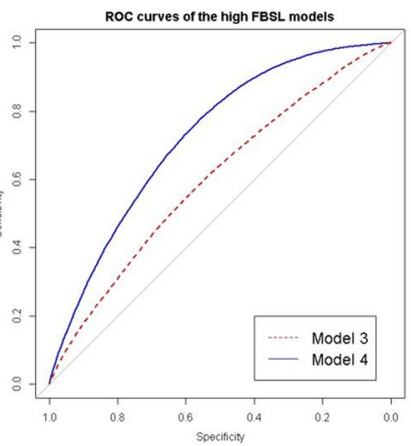

(c)

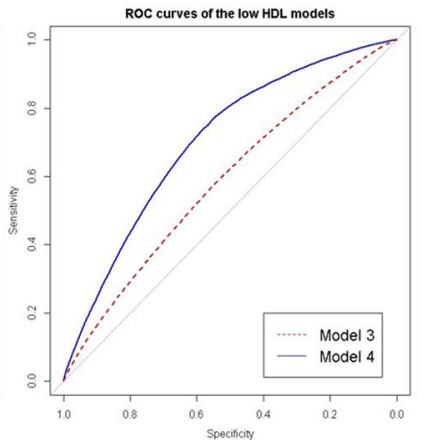

(d)

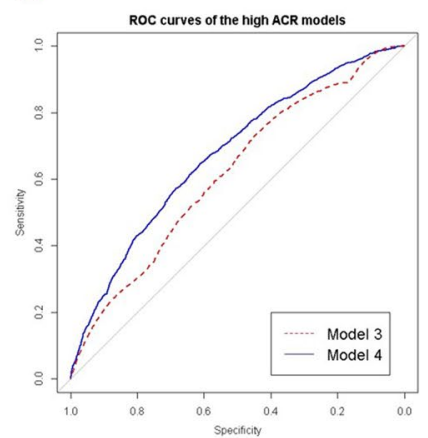

(e)

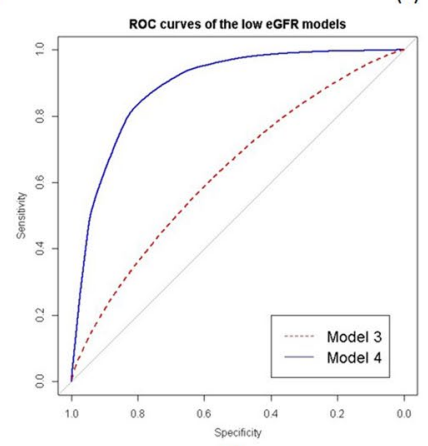

(f)

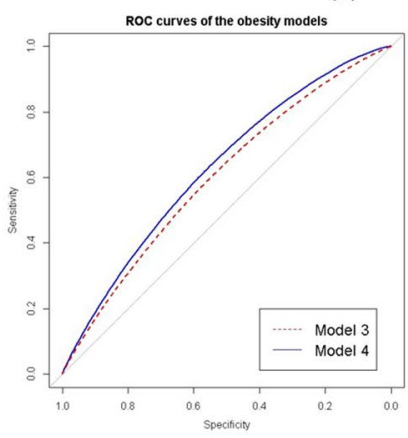

(g)

Figure 2. ROC curves of the fitted models (Model 3s and Model 4s) of CMRFs for comparison: (a) FBSL models; (b) HbAlc models; (c) TC models; (d) HDL models; (e) ACR models; (f) FBSL models; (g) obesity models; Model 3s-CMRFs adjusted only for IRSD quintiles of areas; Model 4s-Final models of CMRFs adjusted for age + sex + IRSD quintiles of area.

\section{Data availability}

Access to, and use of, Southern IML Research (SIMLR) Study data are subject to a License Agreement-Provision of Data (LA) between Southern IML Pathology Pty Ltd (Data Owner) and The University of Wollongong (License Holder), and a Data Access Agreement (DAA) between the License Holder and researchers (Data Users). This process is facilitated by the Illawarra Health and Medical Research Institute (IHMRI) (Data Custodian) through the Southern IML Research Study-Cohort Management Committee (SIMLR-CMC). The Data License does not allow for "public access" to data; however, researcher may access to SIMLR Study data subject to approval by the SIMLR-CMC and an appropriately constituted Australian Human Research Ethics Committee (HREC) as defined in the National Health and Medical Research Council's National Statement on Ethical Conduct in Human Research (2007) (available from https://www.nhmrc.gov.au/about-us/publications/national-statement-ethicalconduct-human-research-2007-updated-2018). The Data License requires at least one of the research team be affiliated with IHMRI. SIMLR-CMC contact details are: C/o-Associate Professor Kathryn Weston; Southern IML Research Study_Cohort Management Committee; Illawarra Health and Medical Research Institute; Building 32, University of Wollongong, Northfields Avenue, Wollongong NSW 2522, Australia; Phone +61 24221 4333; Email: info@ihmri.org.au; Web Link: https://www.ihmri.org.au/research-projects/simlr-cohort-study/.

Received: 27 October 2019; Accepted: 14 July 2020

Published online: 29 July 2020

\section{References}

1. Toms, R., Bonney, A., Mayne, D. J., Feng, X. \& Walsan, R. Geographic and area-level socioeconomic variation in cardiometabolic risk factor distribution: a systematic review of the literature. Int. J. Health Geogr. 18, 1 (2019).

2. Toms, R., Mayne, D. J., Feng, X. \& Bonney, A. Geographic variation in cardiometabolic risk distribution: A cross-sectional study of 256,525 adult residents in the Illawarra-Shoalhaven region of the NSW, Australia. PLoS ONE 14, e0223179 (2019).

3. Alkerwi, A. et al. Geographic variations in cardiometabolic risk factors in Luxembourg. Int. J. Environ. Res. Public Health 14, 648 (2017).

4. Andersen, A. et al. Life-course socio-economic position, area deprivation and Type 2 diabetes: findings from the British Women's Heart and Health Study. Diabetic Med. 25, 1462-1468 (2008).

5. Astell-Burt, T., Feng, X., Kolt, G. S., McLean, M. \& Maberly, G. Understanding geographical inequities in diabetes: multilevel evidence from 114,755 adults in Sydney, Australia. Diabetes Res. Clin. Pract. 106, e68-e73 (2014).

6. Barker, L. E., Kirtland, K. A., Gregg, E. W., Geiss, L. S. \& Thompson, T. J. Geographic distribution of diagnosed diabetes in the US: a diabetes belt. Am. J. Prev. Med. 40, 434-439 (2011).

7. Bonney, A. et al. Area-level socioeconomic gradients in overweight and obesity in a community-derived cohort of health service users-a cross-sectional study. PLoS ONE 10, e0137261 (2015).

8. Congdon, P. Estimating diabetes prevalence by small area in England. J. Public Health (Oxf.) 28, 71-81 (2006).

9. Cubbin, C. et al. Neighborhood deprivation and cardiovascular disease risk factors: protective and harmful effects. Scand. J. Public Health 34, 228-237 (2006). 
10. Dragano, N. et al. Neighbourhood socioeconomic status and cardiovascular risk factors: a multilevel analysis of nine cities in the Czech Republic and Germany. BMC Public Health 7, 255 (2007).

11. Inoue, Y. et al. Neighborhood characteristics and cardiovascular risk among older people in Japan: findings from the JAGES project. PLOS ONE 11, e0164525 (2016).

12. Lawlor, D., Bedford, C., Taylor, M. \& Ebrahim, S. Geographical variation in cardiovascular disease, risk factors, and their control in older women: British Women's Heart and Health Study. J. Epidemiol. Community Health 57, 134-140 (2003).

13. Lawlor, D. A., Davey Smith, G., Patel, R. \& Ebrahim, S. Life-course socioeconomic position, area deprivation, and coronary heart disease: findings from the British Women's Heart and Health Study. Am. J. Public Health 95, 91-97 (2005).

14. Maier, W. et al. Area level deprivation is an independent determinant of prevalent type 2 diabetes and obesity at the national level in Germany. Results from the National Telephone Health Interview Surveys 'German Health Update'GEDA 2009 and 2010. PLoS ONE 9, e89661 (2014).

15. Mujahid, M. S., DiezRoux, A. V., Borrell, L. N. \& Nieto, F. J. Cross-sectional and longitudinal associations of BMI with socioeconomic characteristics. Obes. Res. 13, 1412-1421 (2005).

16. Naimi, A. I., Paquet, C., Gauvin, L. \& Daniel, M. Associations between area-level unemployment, body mass index, and risk factors for cardiovascular disease in an urban area. Int. J. Environ. Res. Public Health 6, 3082-3096 (2009).

17. Roux, A. V. D., Jacobs, D. R. \& Kiefe, C. I. Neighborhood characteristics and components of the insulin resistance syndrome in young adults: the coronary artery risk development in young adults (CARDIA) study. Diabetes Care 25, 1976-1982 (2002).

18. Silhol, R., Zins, M., Chauvin, P. \& Chaix, B. Investigating the spatial variability in incidence of coronary heart disease in the Gazel cohort: the impact of area socioeconomic position and mediating role of risk factors. J. Epidemiol. Community Health 65, 137-143 (2011).

19. Sundquist, K., Eriksson, U., Mezuk, B. \& Ohlsson, H. Neighborhood walkability, deprivation and incidence of type 2 diabetes: a population-based study on 512,061 Swedish adults. Health Place 31, 24-30 (2015).

20. Unger, E. et al. Association of neighborhood characteristics with cardiovascular health in the multi-ethnic study of atherosclerosis. Circ. Cardiovasc. Qual. Outcomes 7, 524-531 (2014).

21. Valdés, S. et al. Prevalence of obesity, diabetes and other cardiovascular risk factors in Andalusia (southern Spain). Comparison with national prevalence data. The Diabetes study. Revista Española de Cardiología (English Edition) 67, 442-448 (2014).

22. Zhou, M. et al. Geographical variation in diabetes prevalence and detection in China: multilevel spatial analysis of 98,058 adults. Diabetes Care 38, 72-81 (2015).

23. Paquet, C. et al. Geographic clustering of cardiometabolic risk factors in metropolitan centres in France and Australia. Int. J. Environ. Res. Public Health 13, 519 (2016).

24. World Health Organisation. The top 10 causes of death. https://www.who.int/news-room/fact-sheets/detail/the-top-10-causes-ofdeath (2017).

25. Australian Institute of Health and Welfare. Indicators of socioeconomic inequalities in cardiovascular disease, diabetes and chronic kidney disease. https://www.aihw.gov.au/getmedia/01c5bb07-592e-432e-9fba-d242e0f7e27e/aihw-cdk-12.pdf.aspx?inline=true (2019).

26. Australian Institute of Health and Welfare. Australian burden of disease study : impact and causes of illness and death in Australia 2011. https://www.aihw.gov.au/getmedia/d4df9251-c4b6-452f-a877-8370b6124219/19663.pdf.aspx?inline=true (2016).

27. Australian Institute of Health and Welfare. Cardiovascular disease, diabetes and chronic kidney disease: Australian facts: morbidity-hospital care. https://www.aihw.gov.au/reports/heart-stroke-vascular-disease/cardiovascular-diabetes-chronic-kidney-morbi dity/contents/table-of-contents (2017).

28. Australian Institute of Health and Welfare. Australia's Health 2014. https://www.aihw.gov.au/reports/australias-health/australias -health-2014/contents/table-of-contents (2014).

29. Clark, C. R. et al. Neighborhood disadvantage, neighborhood safety and cardiometabolic risk factors in African Americans: biosocial associations in the Jackson Heart study. PLoS ONE 8, e63254 (2013).

30. Cox, M., Boyle, P. J., Davey, P. G., Feng, Z. \& Morris, A. D. Locality deprivation and Type 2 diabetes incidence: a local test of relative inequalities. Soc. Sci. Med. 65, 1953-1964 (2007).

31. Gabert, R., Thomson, B., Gakidou, E. \& Roth, G. Identifying high-risk neighborhoods using electronic medical records: a population-based approach for targeting diabetes prevention and treatment interventions. PLoS ONE 11, e0159227 (2016).

32. Keita, A. D. et al. Associations of neighborhood area level deprivation with the metabolic syndrome and inflammation among middle-and older-age adults. BMC Public Health 14, 1319 (2014).

33. Laraia, B. A. et al. Place matters: neighborhood deprivation and cardiometabolic risk factors in the Diabetes Study of Northern California (DISTANCE). Soc. Sci. Med. 74, 1082-1090 (2012).

34. Mobley, L. R. et al. Environment, obesity, and cardiovascular disease risk in low-income women. Am. J. Prev. Med. 30, 327.e321332.e321 (2006).

35. Riva, M., Gauvin, L. \& Barnett, T. A. Toward the next generation of research into small area effects on health: a synthesis of multilevel investigations published since July 1998. J. Epidemiol. Community Health 61, 853-861 (2007).

36. Merlo, J., Wagner, P., Ghith, N. \& Leckie, G. An original stepwise multilevel logistic regression analysis of discriminatory accuracy: the case of neighbourhoods and health. PLoS ONE 11, e0153778 (2016).

37. Merlo, J. et al. Diastolic blood pressure and area of residence: multilevel versus ecological analysis of social inequity. J Epidemiol Community Health 55, 791-798 (2001).

38. Merlo, J., Viciana-Fernández, F. J. \& Ramiro-Fariñas, D. Bringing the individual back to small-area variation studies: a multilevel analysis of all-cause mortality in Andalusia, Spain. Soc. Sci. Med. 75, 1477-1487 (2012).

39. Australian Bureau of Statistics. Australian Statistical Geography Standard (ASGS): Volume 1-Main Structure: Statistical Area Level 1 (SA1). https://www.abs.gov.au/websitedbs/D3310114.nsf/home/Australian+Statistical+Geography+Standard+(ASGS) (2016).

40. The Royal Australian College of General Practitioners \& Diabetes Australia. General Practice Management of Type 2 Diabetes 2016-2018. https://doi.org/10.1007/s00125-010-2011-6 (2016).

41. Australian Bureau of Statistics. Australian Health Survey: Biomedical Results for Chronic Diseases, 2011-2012. https://www.abs. gov.au/AUSSTATS/abs@.nsf/DetailsPage/4364.0.55.0052011-12 (2013).

42. National heart foundation of Australia. Lipid management profile for health professionals. https://www.heartfoundation.org.au/ for-professionals/clinical-information/lipid-management.

43. National Kidney foundation (USA). Albumin creatinine Ratio (ACR). https://www.kidney.org/kidneydisease/siemens_hcp_acr (2018).

44. World Health Organization. Obesity: Preventing and managing the global epidemic: Technical Report Series. WHO Technical Report Series, no. 894. ISBN: 9241208945 (2000).

45. Australian Bureau of Statistics. Main Features_IRSD. https://www.abs.gov.au/ausstats/abs@.nsf/Lookup/2033.0.55.001main+featu res100052011.

46. Ghosh, A., Charlton, K. E., Girdo, L. \& Batterham, M. Using data from patient interactions in primary care for population level chronic disease surveillance: the Sentinel Practices Data Sourcing (SPDS) project. BMC Public Health 14, 557 (2014).

47. Goldstein, H., Browne, W. \& Rasbash, J. Partitioning variation in multilevel models. Underst. Stat. Stat. Issues Psychol. Educ. Soc. Sci. 1, 223-231 (2002).

48. Wagner, P. \& Merlo, J. Measures of discriminatory accuracy in multilevel analysis. Eur. J. Epidemiol. 28, 135 (2013). 
49. Pepe, M. S., Janes, H., Longton, G., Leisenring, W. \& Newcomb, P. Limitations of the odds ratio in gauging the performance of a diagnostic, prognostic, or screening marker. Am. J. Epidemiol. 159, 882-890 (2004).

50. R Core Team. R: A language and environment for statistical computing. $R$ Foundation for Statistical Computing, Vienna, Austria. https://www.R-project.org/ (2018).

51. Bates, D., Mächler, M., Bolker, B. \& Walker, S. Fitting linear mixed-effects models using lme4. arXiv preprint arXiv:1406.5823 (2014).

52. Zeileis, A. \& Hothorn, T. Diagnostic checking in regression relationships. R News 2: 7-10. Accessed August 2011. https://CRAN.Rproject.org/doc/Rnews/ (https://CRAN.R-project.org/doc/Rnews/) (2002).

53. Robin, X. et al. pROC: an open-source package for R and $\mathrm{S}+$ to analyze and compare ROC curves. BMC Bioinform. 12, 77 (2011).

54. Australian Bureau of Statistics. Technical Paper: Socio-Economic Indexes for Areas (SEIFA). https://www.ausstats.abs.gov.au/Ausst ats/subscriber.nsf/0/22CEDA8038AF7A0DCA257B3B00116E34/\$File/2033.0.55.001\%20seifa\%202011\%20technical\%20paper.pdf (2011).

55. Merlo, J., Ohlsson, H., Lynch, K. F., Chaix, B. \& Subramanian, S. Individual and collective bodies: using measures of variance and association in contextual epidemiology. J. Epidemiol. Community Health 63, 1043-1048 (2009).

56. Merlo, J., Wagner, P. \& Leckie, G. A simple multilevel approach for analysing geographical inequalities in public health reports: The case of municipality differences in obesity. Health Place 58, 102145 (2019).

57. Lu, D. \& Tyler, I. Focus on: a proportionate approach to priority populations. Public Health Ontario. https://www.publichealthont ario.ca/en/eRepository/Focus_On_Priority_Populations.pdf. Accessed 29 (2016).

58. Marmot, M. \& Bell, R. Fair society, healthy lives. Public Health 126, S4-S10 (2012).

59. Rose, G. Sick individuals and sick populations. Int. J. Epidemiol. 30, 427-432 (2001).

60. Barter, P. J., Brandrup-Wognsen, G., Palmer, M. K. \& Nicholls, S. J. Effect of statins on HDL-C: a complex process unrelated to changes in LDL-C: analysis of the VOYAGER Database. J. Lipid Res. 51, 1546-1553 (2010).

61. Mooradian, A. D. Dyslipidemia in type 2 diabetes mellitus. Nat. Rev. Endocrinol. 5, 150-159 (2009).

62. Frei, B., Forte, T. M., Ames, B. N. \& Cross, C. E. Gas phase oxidants of cigarette smoke induce lipid peroxidation and changes in lipoprotein properties in human blood plasma. Protective effects of ascorbic acid. Biochem. J. 277, 133-138 (1991).

63. Hu, F. B. Sedentary lifestyle and risk of obesity and type 2 diabetes. Lipids 38, 103-108 (2003).

64. Thorp, A. A. et al. Deleterious associations of sitting time and television viewing time with cardiometabolic risk biomarkers: Australian Diabetes, Obesity and Lifestyle (AusDiab) study 2004-2005. Diabetes Care 33, 327-334 (2010).

65. Arai, T. et al. Increased plasma cholesteryl ester transfer protein in obese subjects. A possible mechanism for the reduction of serum HDL cholesterol levels in obesity. Arterioscle. Thromb. J. Vasc. Biol. 14, 1129-1136 (1994).

66. McNaughton, S. A., Dunstan, D. W., Ball, K., Shaw, J. \& Crawford, D. Dietary quality is associated with diabetes and cardiometabolic risk factors. J. Nutr. 139, 734-742 (2009).

67. Williams, E. D. et al. Health behaviours, socioeconomic status and diabetes incidence: the Australian Diabetes Obesity and Lifestyle Study (AusDiab). Diabetologia 53, 2538-2545 (2010).

68. Sodjinou, R., Agueh, V., Fayomi, B. \& Delisle, H. Obesity and cardio-metabolic risk factors in urban adults of Benin: relationship with socio-economic status, urbanisation, and lifestyle patterns. BMC Public Health 8, 84 (2008)

69. Fraser, L. K., Edwards, K. L., Cade, J. \& Clarke, G. P. The geography of fast food outlets: a review. Int. J. Environ. Res. Public Health 7, 2290-2308 (2010).

70. Macdonald, L., Cummins, S. \& Macintyre, S. Neighbourhood fast food environment and area deprivation-substitution or concentration?. Appetite 49, 251-254 (2007).

71. Pearce, J., Blakely, T., Witten, K. \& Bartie, P. Neighborhood deprivation and access to fast-food retailing: a national study. Am. J. Prev. Med. 32, 375-382 (2007).

72. Walsan, R., Bonney, A., Mayne, D. J., Pai, N., Feng, X. \& Toms, R. Serious mental illness, neighborhood disadvantage, and type 2 diabetes risk: a systematic review of the literature. J. Prim. Care. Community Health 9, 2150132718802025 (2018)

73. Buttar, H. S., Li, T. \& Ravi, N. Prevention of cardiovascular diseases: Role of exercise, dietary interventions, obesity and smoking cessation. Exp. Clin. Cardiol. 10, 229 (2005).

74. Fiuza-Luces, C. et al. Exercise benefits in cardiovascular disease: beyond attenuation of traditional risk factors. Nat. Rev. Cardiol. 15, 731-743 (2018).

75. Chomistek, A. K. et al. Healthy lifestyle in the primordial prevention of cardiovascular disease among young women. J. Am. Coll. Cardiol. 65, 43-51 (2015).

76. $\mathrm{Xu}, \mathrm{H}$. Comparing spatial and multilevel regression models for binary outcomes in neighborhood studies. Sociol. Methodol. 44, 229-272 (2014).

77. Chaix, B., Merlo, J. \& Chauvin, P. Comparison of a spatial approach with the multilevel approach for investigating place effects on health: the example of healthcare utilisation in France. J. Epidemiol. Community Health 59, 517-526 (2005).

78. Toms, R., Feng, X., Mayne, D. J. \& Bonney, A. Role of area-level access to primary care on the geographic variation of cardiometabolic risk factor distribution: a multilevel analysis of the adult residents in the Illawarra-Shoalhaven Region of NSW, Australia. Int. J. Environ. Res. Public Health 17, 4297 (2020).

\section{Acknowledgements}

We would like to thank Southern IML Pathology and staff for their generosity in providing data for the SIMLR Cohort Study and ongoing support. In particular we would like to thank Mr Bryan Jones for providing the technical expertise for the data acquisition and helpful comments on the manuscript. Southern IML Pathology are the owners of the data contained within this publication and the Illawarra Health and Medical Research Institute (IHMRI) is the custodian facilitating access to the data. https://www.ihmri.org.au/research-projects/ simlr-cohort-study/

\section{Author contributions}

R.T. contributed to the study conceptualization, data curation, statistical analyses, and writing of the original draft; D.M. contributed to the study conceptualization, methodology and co-supervision of the project; X.F. contributed to the study methodology and co-supervision of the project; and A.B. contributed to the overall project administration, resources, methodology, and main supervision of the project and study validation. All the authors reviewed the manuscript.

\section{Competing interests}

The authors declare no competing interests. 


\section{Additional information}

Correspondence and requests for materials should be addressed to R.T.

Reprints and permissions information is available at www.nature.com/reprints.

Publisher's note Springer Nature remains neutral with regard to jurisdictional claims in published maps and institutional affiliations.

(c) (1) Open Access This article is licensed under a Creative Commons Attribution 4.0 International License, which permits use, sharing, adaptation, distribution and reproduction in any medium or format, as long as you give appropriate credit to the original author(s) and the source, provide a link to the Creative Commons license, and indicate if changes were made. The images or other third party material in this article are included in the article's Creative Commons license, unless indicated otherwise in a credit line to the material. If material is not included in the article's Creative Commons license and your intended use is not permitted by statutory regulation or exceeds the permitted use, you will need to obtain permission directly from the copyright holder. To view a copy of this license, visit http://creativecommons.org/licenses/by/4.0/.

(c) The Author(s) 2020 